\title{
Serum substance $P$ levels are associated with severity and mortality in patients with severe traumatic brain injury
}

Leonardo Lorente ${ }^{1 *}$, María M Martín ${ }^{2}$, Teresa Almeida ${ }^{3}$, Mariano Hernández $^{3}$, Luis Ramos ${ }^{4}$, Mónica Argueso $^{5}$, Juan J Cáceres ${ }^{6}$, Jordi Solé-Violán ${ }^{7}$ and Alejandro Jiménez ${ }^{8}$

\begin{abstract}
Introduction: Substance P (SP) is a member of the tachykinin family of neuropeptides, which are widely distributed throughout the central nervous system (CNS) and actively involved in inflammatory processes. SP is released early following acute injury to the CNS, promoting a neurogenic inflammatory response characterized by an increase in the permeability of the blood-brain barrier and the development of vasogenic edema. High levels of SP could lead to an exacerbated inflammatory response that could be fatal for patients with traumatic brain injury (TBI). Thus, the main goal of the present study was to determine whether serum SP levels are associated with injury severity and mortality in patients with severe TBI.
\end{abstract}

Methods: This multicenter, observational, prospective study was carried out in six Spanish intensive care units and included patients with Glasgow Coma Scale (GCS) scores $\leq 8$. Patients with an Injury Severity Score $\geq 10$ in non-cranial aspects were excluded. Blood samples were collected on day 1 of TBI to measure serum SP levels. The endpoint was 30-day mortality.

Results: We found higher serum SP levels $(P=0.002)$ in non-surviving patients $(n=27)$ than in surviving patients $(n=73)$. The area under the curve for serum SP levels with regard to predicting 30-day mortality was 0.70 ( $95 \%$ confidence interval $(\mathrm{Cl}), 0.60$ to $0.79 ; P<0.001$ ). Survival analysis showed that patients with serum SP levels $>299 \mathrm{pg} / \mathrm{ml}$ had higher 30 -day mortality than patients with lower levels (hazard ratio $=3.7 ; 95 \% \mathrm{Cl}, 1.75$ to $7.94 ; P<0.001$ ). Multiple binomial logistic regression analysis showed that serum SP levels $>299 \mathrm{pg} / \mathrm{ml}$ were associated with 30-day mortality when we controlled for APACHE II score and Marshall computed tomography lesion classification (odds ratio (OR) $=5.97 ; 95 \% \mathrm{Cl}, 1.432$ to $24.851 ; P=0.01)$ and for $\mathrm{GCS}$ score and age $(\mathrm{OR}=5.71 ; 95 \% \mathrm{Cl}, 1.461$ to $22.280 ; P=0.01)$. We found a negative association between serum SP levels and GCS score (Spearman's $\rho=-0.22 ; P=0.03$ ).

Conclusions: We report, for the first time to our knowledge, that serum SP levels were associated with injury severity and mortality in patients with severe TBI. These results open the possibility that SP antagonists may be useful in the treatment of patients with severe TBl.

\section{Introduction}

Traumatic brain injury (TBI) is a leading cause of death, disability and resource consumption [1]. There are two kinds of brain injury in TBI: primary and secondary injuries. Primary injury refers to the initial physical forces applied to the brain at the moment of impact and leads to shearing, laceration and stretching of nerve fibers

\footnotetext{
* Correspondence: lorentemartin@msn.com

'Intensive Care Unit, Hospital Universitario de Canarias, Ofra, s/n La Laguna, 38320 Tenerife, Spain

Full list of author information is available at the end of the article
}

[2,3]. Secondary injury is a term applied to the destructive and self-propagating biological changes in cells and tissues that lead to their dysfunction or death during the hours to weeks after the initial insult [4]. One of the process that contribute to these biological changes is neurogenic inflammation, characterized by the release of substances from primary sensory nerves, leading to vasodilation, protein extravasation and tissue swelling $[5,6]$. Substance P (SP), calcitonin gene-related peptide and neurokinin A are neuropeptides present in the sensory $\mathrm{C}$ fibers that densely surround cerebral blood vessels $[7,8]$. 
Among them, SP has been generally accepted to be associated with increased microvascular permeability and edema formation [9-11]. It is widely accepted that the development of edema has adverse consequences in TBI outcome through effects on intracranial pressure [12].

Apart from neurogenic inflammation, SP is also involved in the classical inflammatory response mediated by activation of its preferred neurokinin 1 receptor (NK1R), which is widely distributed throughout the central nervous system (CNS) [13]. Brain injury increases NK1R expression in neurons and astrocytes [14], and SP, acting through this receptor, leads to astrocyte activation. Reactive astrocytes proliferate and produce several soluble proinflammatory mediators, such as cytokines, prostaglandins and thromboxane derivatives [14-17]. In addition, both SP and NK1R are expressed in microglial cells, which are involved in initiation and/or progression of immune responses within the CNS [17]. Microglia respond to traumatic injury by migrating to the site of challenge, where they assume many of the immune effector functions typically associated with macrophages [17]. Stimulation of microglia by SP initiates activation of nuclear factor $\kappa \mathrm{B}(\mathrm{NF}-\mathrm{\kappa} B)$, a transcriptional activator involved in expression of proinflammatory cytokines [18]. In fact, microglia produce interleukin (IL)-1 in response to SP [19]. Apart from microglia, other brain cells can be activated by SP. In this sense, it has been shown that SP interacts with NK1R receptors present on the human neuronal cell line NT2N, inducing the expression of the potent chemokine macrophage inflammatory protein 1 [20]. In addition, SP can activate the transcription factors NF- $\mathrm{KB}$ and p38 mitogen-activated protein kinase in astrocyte cell lines, leading to the production of the proinflammatory cytokines IL1, IL-6 and IL-8 [21-23]. Finally, SP can promote leukocyte chemotaxis through NK1R expressed in many inflammatory and immune cells, leading to the extravasation, migration and subsequent accumulation of leukocytes at sites of injury $[5,24]$. Infiltrating immune cells can contribute to the production of proinflammatory signals [25-28].

All these data suggest that SP is actively involved in the inflammatory processes following brain injury. Although SP increases after damage can be beneficial in fighting host infections associated with TBI [29], it may also play an important role in exacerbating inflammatory immune responses in the CNS, which may be fatal for patients with TBI. We therefore framed our hypothesis by testing whether serum SP levels were associated with injury severity and mortality in patients with severe TBI and whether these levels would be clinically useful in predicting mortality in these patients.

\section{Material and methods Design and subjects}

This was a multicenter, observational, prospective study carried out in six intensive care units in Spain between
2009 and 2012. We included patients with severe TBI, defined as Glasgow Coma Scale (GCS) [30] score $\leq 8$ points. We excluded individuals $<18$ years of age and those with pregnancy, inflammatory diseases (such as asthma, sarcoidosis, chronic obstructive pulmonary disease, inflammatory bowel disease and rheumatoid arthritis), malignant diseases or Injury Severity Score (ISS) [31] $\geq 10$ points in non-cranial aspects. A total of 100 patients were included in the study, and they were treated according to the Brain Trauma Foundation guidelines [1].

The study was approved by the institutional review boards of the six participating hospitals: Hospital Universitario de Canarias (La Laguna, Santa Cruz de Tenerife, Spain), Hospital Universitario Nuestra Señora de Candelaria (Santa Cruz de Tenerife, Spain), Hospital General de La Palma (La Palma, Spain), Hospital Clínico Universitario de Valencia (Valencia, Spain), Hospital Insular (Las Palmas de Gran Canaria, Spain) and Hospital Universitario Dr Negrín (Las Palmas de Gran Canaria, Spain). Written informed consent was obtained from the patients or their legal guardians.

\section{Variables recorded}

Blood samples were analyzed for glycemia, sodium, lactic acid, creatinine, bilirubin, hemoglobin, platelets, fibrinogen, international normalized ratio, activated partial thromboplastin time (aPTT) and leukocytes. Brain lesions were classified according to the Marshall computed tomography (CT) criteria [32]. To estimate the clinical severity, we calculated GCS, ISS and Acute Physiology and Chronic Health Evaluation II (APACHE II) scores [33].

The Marshall CT lesion classification scheme [32] is as follows:

- Class I or diffuse injury I: no visible pathology

- Class II or diffuse injury II: presence of cisterns with midline shift 0 to $5 \mathrm{~mm}$ and no high- or mixeddensity lesion $>25 \mathrm{ml}$

- Class III or diffuse injury III (swelling): cisterns compressed or absent with midline shift 0 to $5 \mathrm{~mm}$ and no high- or mixed-density lesion $>25 \mathrm{ml}$

- Class IV or diffuse injury IV (shift): midline shift $>5 \mathrm{~mm}$ and no high-or mixed-density lesion $>25 \mathrm{ml}$

- Class V or evacuated mass lesion: any lesion evacuated

- Class VI or non-evacuated mass lesion: high- or mixed-density lesion $>25 \mathrm{ml}$ not surgically evacuated

\section{Endpoint}

The endpoint of the study was 30-day mortality.

\section{Substance $P$ assay}

A total of $5 \mathrm{ml}$ of venous blood samples were collected on day 1 of TBI (within the first 4 hours after TBI) through a central venous catheter. The blood was added to serum 
separator tubes, allowed to clot at room temperature for 30 minutes and then centrifuged at $1,000 \times g$ for $15 \mathrm{mi}-$ nutes. Serum was removed and frozen at $-80^{\circ} \mathrm{C}$ until SP measurement.

SP assay was performed in the Genetics Unit of the Instituto de Enfermedades Tropicales y Salud Pública de Canarias of the University of La Laguna (Tenerife, Spain). Serum SP levels were assayed by specific enzyme-linked immunosorbent assay according to the manufacturer's instructions (R\&D Systems, Abingdon, UK). All samples were assayed in duplicate at twofold dilutions in assay buffer. Absorbance at $450 \mathrm{~nm}$ was measured using the EnSpire multimode plate reader (PerkinElmer, Waltham, MA, USA). The serum concentration of SP was expressed in picograms per milliliter. The detection limit of this assay was $25 \mathrm{pg} / \mathrm{ml}$, and the intra- and interassay coefficients of variation were $9 \%$ and $15 \%$, respectively. Samples were all processed at the same time, at the end of the recruitment process, by the same laboratory technician using the same equipment and blinded to all clinical data.

\section{Statistical methods}

Continuous variables are reported as medians and interquartile ranges, and comparisons between groups were carried out using the Wilcoxon-Mann-Whitney test. We used the Kolmogorov-Smirnov test to compare the frequencies distribution of our continuous variables with the theoretical normal distribution. Because lack of normality was observed in some variables included in the analysis, we used nonparametric tests to compare groups. Categorical variables are reported as frequencies and percentages, and comparisons between groups were carried out with the $\chi^{2}$ test.

Receiver operating characteristic curve analysis was carried out to determine the area under the curve (AUC). Kaplan-Meier analysis of 30-day survival was carried out using serum SP levels higher or lower than $299 \mathrm{pg} / \mathrm{ml}$ as the independent variable and survival at 30 days as the dependent variable. Comparisons were performed using the log-rank test. We used the Youden index (J) to select the cutoff point of serum SP level for the prediction of mortality at 30 days.

Multiple binomial logistic regression analyses were carried out to determine the association between serum SP levels and mortality at 30 days. In the first model, we included CT findings with high risk of death (classes III, IV and VI), APACHE II score and serum SP levels $>299 \mathrm{pg} / \mathrm{ml}$. In the second model, we included age, GCS score and serum SP levels $>299 \mathrm{pg} / \mathrm{ml}$. Odds ratios (ORs) and 95\% confidence intervals (CIs) were calculated as measures of the clinical impact of the predictor variables.

A $P$-value $<0.05$ was considered statistically significant. Statistical analyses were performed with IBM SPSS 17.0 (IBM, Armonk, NY, USA), NCSS 2000 (Kaysville,
UT, USA) and LogXact 4.1 (Cytel, Cambridge, MA, USA) software.

\section{Results}

Comparisons of demographic and clinical severity data between surviving and non-surviving patients with TBI are shown in Table 1. We found a higher ratio of female patients among non-survivors than among survivors (11 (40.7\%) of 27 vs $12(16.4 \%)$ of 73 , respectively; $P=0.02$ ). There were statistically significant differences in CT findings between non-surviving and surviving patients $(P=0.002)$. We found a higher rate of CT findings with high risk of death (classes III, IV and VI) in non-surviving than in surviving patients $(19$ (70.4\%) of 27 vs $26(35.6 \%)$ of 73 , respectively; $P=0.003)$. Non-surviving patients with TBI had lower GCS scores $(P<0.001)$, were older $(P<0.001)$ and had higher APACHE II scores $(P<0.001)$ than survivors. In addition, non-surviving patients had higher serum SP levels than survivors $(P=0.002)$.

The AUC for serum SP levels as a predictor of 30-day mortality was $0.70(95 \% \mathrm{CI}, 0.60$ to $0.79 ; P<0.001)$ (Figure 1).

Survival analysis showed that patients with serum SP levels $>299 \mathrm{pg} / \mathrm{ml}$ had higher 30-day mortality than patients with lower levels (hazard ratio $=3.7 ; 95 \% \mathrm{CI}, 1.75$ to $7.94 ; P<0.001$ ) (Figure 2).

Multiple binomial logistic regression analysis showed that serum SP levels $>299 \mathrm{pg} / \mathrm{ml}$ were associated with 30-day mortality when we controlled for APACHE II score and CT classification (OR $=5.97 ; 95 \% \mathrm{CI}, 1.432$ to 24.851; $P=0.01)$ and for GCS score and age (OR =5.71; 95\% CI, 1.461 to 22.280; $P=0.01$ ) (Table 2).

We found no significant differences in serum SP levels between female and male patients (222 (135 to 493) vs 319 (157 to 547$) \mathrm{pg} / \mathrm{ml}$, respectively; $P=0.35$ ). Similarly, no association was observed between serum SP levels and intracranial pressure (Spearman's $\rho=-0.10 ; P=0.26$ ). On the contrary, we found a negative association between serum SP levels and GCS (Spearman's $\rho=-0.22 ; P=0.03$ ).

\section{Discussion}

To our knowledge, this is the first study report of serum SP levels in patients with severe TBI. Our data support an important role of SP in TBI on the basis of our findings: (1) Non-surviving TBI patients showed significantly higher serum SP levels than survivors; (2) serum SP levels were significantly associated with early mortality, suggesting its potential as a biomarker; and (3) serum SP levels were significantly associated with TBI severity. Taken together, all these findings suggest that serum SP levels may be of great pathophysiological significance in patients with TBI. We also found that other variables, such as age, GCS score and CT findings, were associated with 30-day mortality, which is in agreement with previous studies [34-38]. 
Table 1 Comparison of demographic and clinical severity data between traumatic brain injury survivors and non-survivors ${ }^{a}$

\begin{tabular}{|c|c|c|c|}
\hline & Non-survivors $(n=27)$ & Survivors $(n=73$ ) & $P$-value \\
\hline Glasgow Coma Scale score & 3 (3 to 6$)$ & 7 (6 to 8$)$ & $<0.001$ \\
\hline APACHE II score & 26 (25 to 32$)$ & 19 (17 to 23$)$ & $<0.001$ \\
\hline Age (yr) & 66 (45 to 76$)$ & 47 (32 to 67 ) & $<0.001$ \\
\hline Substance P (pg/ml) & 420 (310 to 815$)$ & 250 (99 to 496$)$ & 0.002 \\
\hline$C T$ findings & & & 0.002 \\
\hline Class I & 0 & 0 & \\
\hline Class ॥ & $3(11.1)$ & $21(28.8)$ & \\
\hline Class III & $5(18.5)$ & $13(17.8)$ & \\
\hline Class IV & $6(22.2)$ & $10(13.7)$ & \\
\hline Class V & $5(18.5)$ & $26(35.6)$ & \\
\hline Class VI & $8(29.6)$ & $3(4.1)$ & \\
\hline Female sex & $11(40.7)$ & $12(16.4)$ & 0.02 \\
\hline Temperature $\left({ }^{\circ} \mathrm{C}\right)$ & 36.0 (35.0 to 37.0$)$ & 37.0 (35.6 to 37.3$)$ & 0.12 \\
\hline Sodium (mEq/L) & 141 (135 to 149$)$ & 139 (138 to 142$)$ & 0.19 \\
\hline Platelets $\left({ }^{*} 10^{3} / \mathrm{mm}^{3}\right)$ & 215 (139 to 264) & 182 (143 to 252$)$ & 0.48 \\
\hline $\mathrm{PaO}_{2}(\mathrm{mmHg})$ & 141 (104 to 186$)$ & 151 (116 to 217$)$ & 0.34 \\
\hline $\mathrm{PaO}_{2} / \mathrm{FiO}_{2}$ ratio & 190 (154 to 316) & 336 (242 to 407$)$ & 0.11 \\
\hline Leukocytes $\left({ }^{*} 10^{3} / \mathrm{mm}^{3}\right)$ & $18.3(10.7$ to 23.9$)$ & $14.7(10.2$ to 19.3$)$ & 0.46 \\
\hline Lactic acid (mmol/L) & $1.90(1.15$ to 4.55$)$ & $1.70(1.23$ to 2.50$)$ & 0.16 \\
\hline Intracranial pressure (mmHg) & $20(12$ to 30$)$ & 15 (14 to 20$)$ & 0.27 \\
\hline International normalized ratio & $1.22(1.01$ to 1.67$)$ & $1.03(0.92$ to 1.15$)$ & 0.15 \\
\hline Injury Severity Score & 25 (25 to 27$)$ & 25 (25 to 32$)$ & 0.24 \\
\hline Hemoglobin (g/dl) & $11.1(9.4$ to 12.3$)$ & $11.4(10.4$ to 13.0$)$ & 0.87 \\
\hline Glycemia (g/dl) & 161 (142 to 189$)$ & 139 (120 to 163$)$ & 0.08 \\
\hline Fibrinogen (mg/dl) & 376 (246 to 560$)$ & 350 (282 to 444$)$ & 0.32 \\
\hline Creatinine (mg/dl) & 0.95 (0.70 to 1.10$)$ & $0.80(0.70$ to 0.90$)$ & 0.44 \\
\hline Cerebral perfusion pressure $(\mathrm{mmHg})$ & 60 (54 to 69) & 68 (57 to 70$)$ & 0.46 \\
\hline Bilirubin (mg/dl) & 0.75 (0.53 to 1.05$)$ & 0.50 (0.40 to 0.87$)$ & 0.045 \\
\hline aPTT (seconds) & 26 (25 to 31$)$ & 28 (25 to 32$)$ & 0.86 \\
\hline
\end{tabular}

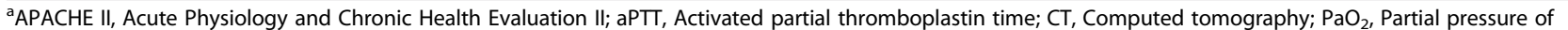
arterial oxygen; $\mathrm{PaO}_{2} / \mathrm{FiO}_{2}$ ratio, Ratio of partial pressure of arterial oxygen to fraction of inspired oxygen. Data shown are number (percentage) or median (25th to 75th percentiles).

SP stimulates mitogenesis in different cell types, including adult neural progenitor cells [39]; increases axonal growth from the dorsal horn [40]; and promotes neurite outgrowth [41]. In spite of this beneficial action on neurogenesis, several studies carried out in animal models support a deleterious role of SP in TBI. In rats, SP release after severe diffuse TBI increased vascular permeability and edema formation, both of which were attenuated after administration of a NK1R antagonist [10,11]. SP can promote proliferation [42], chemotaxis [43] and activation of microglia [18,25], and the subsequent release of proinflammatory cytokines by activated cells may impair neurogenesis and motor outcome [44-46]. In fact, treatment of rats with a NK1R antagonist after TBI improved functional outcome [42]. In addition, proinflammatory mediators can be released by other brain cells expressing NK1R in response to SP, such as astrocytes and neuronal cells, contributing to an increase in the inflammatory response [20-23]. Finally, capsaicin, a substance that induces SP depletion from sensory nerves, administered to rats before TBI attenuated blood brainbarrier opening, edema formation and the development of both motor and cognitive deficits [6]. These results obtained in small animal models have been reproduced using an ovine model of TBI [47]. In this model, administration of a NK1R antagonist decreased edema formation and caused a profound reduction in posttraumatic intracranial pressure. In humans, a recent study carried out with archival postmortem material found increased SP immunoreactivity 


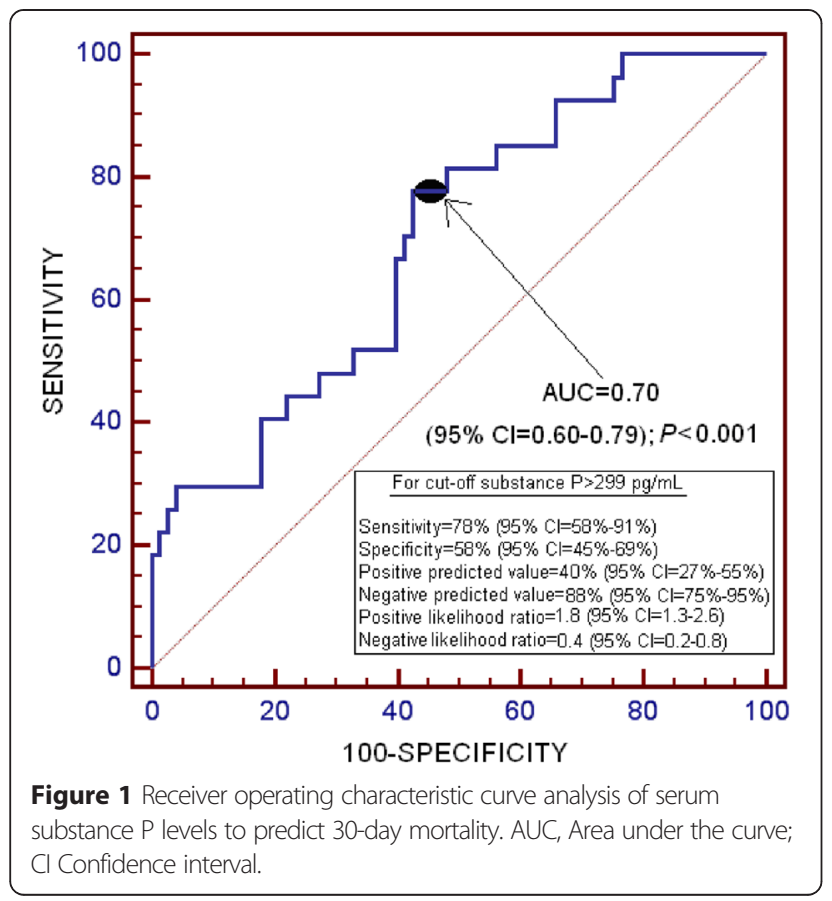

in different brain areas of patients who experienced TBI compared with patients with no neuropathological abnormality [7].

Taking into account all these data, we proposed that brain injury in humans induces SP release from sensory neurons, which trigger a cascade of events that results in activation of NK1R in cerebral blood vessels, leading to increased vascular permeability and edema formation. In addition, activation of neurons, astrocytes and microglia by SP leads to inhibition of neurogenesis and chemotaxis of inflammatory and immune cells to the site of injury. Inflammatory cells may use SP as a paracrine or autocrine signaling mechanism to propagate inflammation beyond the limited topographic spread of the sensory neurons [48]. The concentration of neuroimmune SP increases in the brain, leaking into the bloodstream, where it can be quantitated in serum or plasma samples. This measurement would allow identification of those patients with an exacerbated inflammatory response. This is particularly interesting because NK1R antagonists have been approved for commercial use to treat different pathologies [49-51], and they could be an attractive therapeutic option for these patients [52].

The observed association of SP with higher mortality may be due to malignant and inflammatory conditions that are known to increase SP levels [53-55]. However, patients with diseases such as asthma, sarcoidosis, chronic obstructive pulmonary disease, inflammatory bowel disease, rheumatoid arthritis or malignant diseases were not included in the present study. Even so, we cannot discount the possibility that other conditions may influence SP levels. Elevated serum SP levels could reflect greater injury severity and hence higher mortality. However, multiple logistic regression analysis showed that serum SP levels were associated with mortality after we controlled for GCS and APACHE II scores and age.

Previous studies have shown that serum SP levels vary considerably over time after TBI [10]. Thus, as soon as
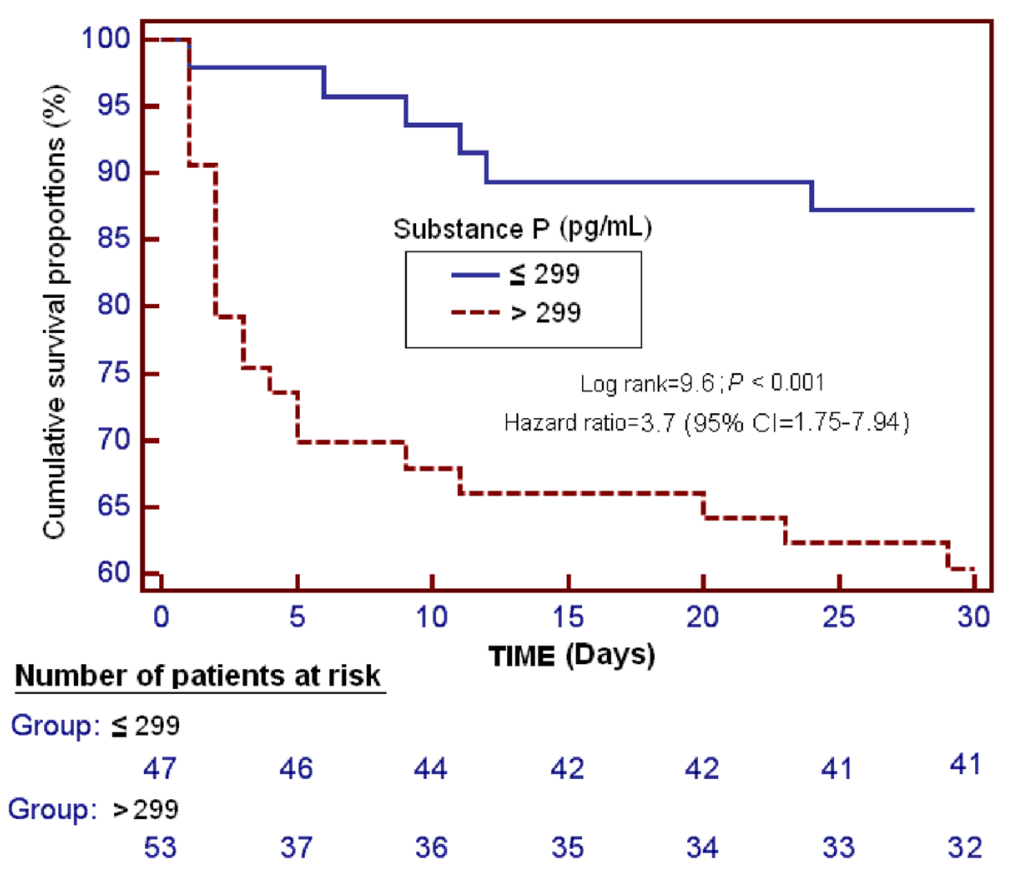

Figure 2 Survival curves at 30 days using serum substance P levels higher or lower than $299 \mathrm{pg} / \mathrm{ml}$ as the cutoff. Cl, Confidence interval. 
Table 2 Multiple binomial logistic regression analysis to predict 30-day mortality ${ }^{a}$

\begin{tabular}{|c|c|c|c|}
\hline & Odds ratio & 95\% confidence interval & $P$-value \\
\hline \multicolumn{4}{|l|}{ First model } \\
\hline APACHE II score & 1.39 & 1.188 to 1.622 & $<0.001$ \\
\hline CT with high risk of death (classes III, IV and VI) & 4.61 & 1.067 to 19.967 & 0.04 \\
\hline Serum substance P levels $>299 \mathrm{pg} / \mathrm{ml}$ & 6.64 & 1.507 to 29.238 & 0.01 \\
\hline Sex female & 2.66 & 0.591 to 11.966 & 0.20 \\
\hline \multicolumn{4}{|l|}{ Second model } \\
\hline Age & 1.08 & 1.029 to 1.122 & $<0.001$ \\
\hline GCS score & 0.56 & 0.396 to 0.776 & $<0.001$ \\
\hline Serum substance P levels $>299 \mathrm{pg} / \mathrm{ml}$ & 7.28 & 1.650 to 32.086 & 0.01 \\
\hline Female sex & 3.92 & 0.765 to 20.118 & 0.10 \\
\hline
\end{tabular}

${ }^{\mathrm{a}}$ APACHE II, Acute Physiology and Chronic Health Evaluation; CT, Computed tomography; GCS, Glasgow Coma Scale.

30 minutes after injury, a significant increase in serum SP levels was observed in mice, but these levels decreased by 5 hours, presumably due to rapid proteolysis by non-specific serum proteases [10]. In our study, all samples were collected within 4 hours after TBI, although the exact interval between the injury, hospital admission and blood collection were not recorded. In addition, we did not analyze serum SP levels during follow-up. Therefore, information regarding sample collection period and patient monitoring would be desirable in future studies to determine the role of SP in TBI.

Although the mortality rate in our series (27\%) is similar to that reported in other studies [56,57], it should be noted that the mortality rate may be different in series with a different case mix (that is, with regard to GCS, APACHE II, age and CT findings). Moreover, owing to the low number of events (deaths), we included only three variables in the multiple logistic regression analysis to avoid a final model of order slightly higher than required due to an overfitting effect [58]. In addition, in the multiple regression analysis, we included those variables that showed statistically significant differences in the bivariate analysis when survivors and nonsurvivors were compared. We also used two models to avoid the effects of collinearity. Thus, we constructed two multiple binomial logistic regression models with only three predictor variables in each model, including serum SP levels in both models. One model controlled for CT findings and APACHE II score, and the other controlled for age and GCS score. We found that serum SP levels were associated with mortality in both models, which strongly supports the role of SP in TBI. However, larger series of patients and the inclusion of more variables in a single multiple logistic regression analysis are needed to confirm our findings.

\section{Conclusions}

The most relevant findings of our study, which is the first to include data on serum SP levels in patients with severe TBI to our knowledge, are that non-surviving TBI patients showed higher serum SP levels than survivors, that serum SP levels were associated with severity and mortality, and that serum SP levels could be used as a biomarker to predict mortality in patients with severe TBI. These results open the possibility that NK1R antagonists may be useful for the treatment of severe TBI.

\section{Key messages}

- Serum substance P levels are associated with TBI severity.

- Non-surviving TBI patients showed higher serum substance P levels than survivors.

- Serum substance P levels are associated with TBI mortality.

\section{Abbreviations}

APACHE: Acute Physiology and Chronic Health Evaluation; aPTT: Activated partial thromboplastin time; AUC: Area under the curve; Cl: Confidence interval; CNS: Central nervous system; CT: Computed tomography; $\mathrm{FiO}_{2}$ : Fraction of inspired oxygen; GCS: Glasgow Coma Scale; IL: Interleukin; ISS: Injury Severity Score; NF-KB: Nuclear factor KB; NK1R: Neurokinin 1 receptor; OR: Odds ratio; $\mathrm{PaO}_{2}$ : Partial pressure of arterial oxygen; SP: Substance P; TBI: Traumatic brain injury.

\section{Competing interests}

The authors declare that they have no competing interests.

\section{Authors' contributions}

LL conceived, designed and coordinated the study; participated in acquisition of data; and, together with $\mathrm{TA}$ and $\mathrm{MH}$, drafted the manuscript. MMM, TA, MH, LR, MA, JJC and JSV participated in acquisition of data and provided useful suggestions. AJ interpreted the data and provided useful suggestions. TA and MH carried out the immunoassays and provided useful suggestions. All authors read and approved the final manuscript.

\section{Acknowledgments}

We thank Andreína León Carmenatis and Henoc del Rosario García for their technical assistance. This study was supported by the Fundación Canaria de Investigación Sanitaria (FUNCANIS) (La Laguna, Tenerife, Spain). The funders had no role in study design, sample collection, data analysis, decision to publish or preparation of the manuscript. 


\section{Author details}

${ }^{1}$ Intensive Care Unit, Hospital Universitario de Canarias, Ofra, s/n La Laguna, 38320 Tenerife, Spain. ${ }^{2}$ Intensive Care Unit, Hospital Universitario Nuestra Señora Candelaria, Carretera del Rosario s/n, 38010 Santa Cruz Tenerife, Spain. ${ }^{3}$ Unidad de Genética, Instituto de Enfermedades Tropicales y Salud Pública de Canarias, Universidad de La Laguna, Avenida Astrofísico Francisco Sánchez s/n, Campus de Anchieta, La Laguna, 38071 Tenerife, Spain. ${ }^{4}$ Intensive Care Unit, Hospital General La Palma, Buenavista de Arriba s/n, Breña Alta, 38713 La Palma, Spain. ${ }^{5}$ Intensive Care Unit, Hospital Clínico Universitario de Valencia, Avenida Blasco Ibáñez n 17-19, 46004 Valencia, Spain. ${ }^{6}$ Intensive Care Unit, Hospital Insular, Plaza Dr Pasteur s/n, 35016 Las Palmas de Gran Canaria, Spain. ${ }^{7}$ Intensive Care Unit, Hospital Universitario Dr Negrín, Centro de Investigación Biomédica en Red Enfermedades Respiratorias (CIBERES), Barranco de la Ballena s/n, 35010 Las Palmas de Gran Canaria, Spain. ${ }^{8}$ Research Unit, Hospital Universitario de Canarias, Ofra, s/n, La Laguna, 38320 Santa Cruz de Tenerife, Spain.

Received: 31 January 2015 Accepted: 4 April 2015

Published online: 27 April 2015

\section{References}

1. Brain Trauma Foundation, American Association of Neurological Surgeons, Congress of Neurological Surgeons. Guidelines for the management of severe traumatic brain injury. J Neurotrauma. 2007;24 Suppl 1:S1-S106.

2. Graham DI, Clark JC, Adams JH, Gennarelli TA. Diffuse axonal injury caused by assault. J Clin Pathol. 1992;45:840-1.

3. Graham DI, Gentleman SM, Nicoll JA, Royston MC, McKenzie JE, Roberts GW, et al. Altered $\beta$-APP metabolism after head injury and its relationship to the aetiology of Alzheimer's disease. Acta Neurochir Suppl. 1996;66:96-102.

4. Borgens RB, Liu-Snyder P. Understanding secondary injury. Q Rev Biol. 2012:87:89-127.

5. De Swert KO, Joos GF. Extending the understanding of sensory neuropeptides. Eur J Pharmacol. 2006;533:171-81.

6. Nimmo AJ, Cernak I, Heath DL, Hu X, Bennett CJ, Vink R. Neurogenic inflammation is associated with development of edema and functional deficits following traumatic brain injury in rats. Neuropeptides. 2004;38:40-7.

7. Zacest AC, Vink R, Manavis J, Sarvestani GT, Blumbergs PC. Substance P immunoreactivity increases following human traumatic brain injury. Acta Neurochir Suppl. 2010;106:211-6.

8. Edvinsson L, Brodin E, Jansen I, Uddman R. Neurokinin A in cerebral vessels: characterization, localization and effects in vitro. Regul Pept. 1988;20:181-97.

9. Newbold P, Brain SD. An investigation into the mechanism of capsaicininduced oedema in rabbit skin. Br J Pharmacol. 1995;114:570-7.

10. Donkin JJ, Nimmo AJ, Cernak I, Blumbergs PC, Vink R. Substance $P$ is associated with the development of brain edema and functional deficits after traumatic brain injury. J Cereb Blood Flow Metab. 2009;29:1388-98.

11. Donkin JJ, Cernak I, Blumbergs PC, Vink R. A substance P antagonist reduces axonal injury and improves neurologic outcome when administered up to 12 hours after traumatic brain injury. J Neurotrauma. 2011;28:217-24.

12. Marmarou A, Fatouros PP, Barzó P, Portella G, Yoshihara M, Tsuji O, et al. Contribution of edema and cerebral blood volume to traumatic brain swelling in head-injured patients. J Neurosurg. 2000;93:183-93. A published erratum appears in J Neurosurg. 2001;94:349.

13. Donkin JJ, Turner RJ, Hassan I, Vink R. Substance P in traumatic brain injury. Prog Brain Res. 2007;161:97-109.

14. Mantyh PW, Johnson DJ, Boehmer CG, Catton MD, Vinters HV, Maggio JE, et al. Substance $P$ receptor binding sites are expressed by glia in vivo after neuronal injury. Proc Natl Acad Sci U S A. 1989;86:5193-7.

15. Marriott DR, Wilkin GP, Wood JN. Substance P-induced release of prostaglandins from astrocytes: regional specialisation and correlation with phosphoinositol metabolism. J Neurochem. 1991;56:259-65.

16. Palma C, Minghetti L, Astolfi M, Ambrosini E, Silberstein FC, Manzini S, et al. Functional characterization of substance $P$ receptors on cultured human spinal cord astrocytes: synergism of substance $P$ with cytokines in inducing interleukin-6 and prostaglandin $E_{2}$ production. Glia. 1997;21:183-93.

17. Marriott I. The role of tachykinins in central nervous system inflammatory responses. Front Biosci. 2004;9:2153-65.

18. Rasley A, Bost KL, Olson JK, Miller SD, Marriott I. Expression of functional NK-1 receptors in murine microglia. Glia. 2002;37:258-67.
19. Martin FC, Anton PA, Gornbein JA, Shanahan F, Merrill JE. Production of interleukin-1 by microglia in response to substance $P$ : role for a non-classical NK-1 receptor. J Neuroimmunol. 1993;42:53-60.

20. Li Y, Douglas SD, Pleasure DE, Lai J, Guo C, Bannerman P, et al. Human neuronal cells (NT2-N) express functional substance $P$ and neurokinin-1 receptor coupled to MIP-1 $\beta$ expression. J Neurosci Res. 2003:71:559-66.

21. Lieb K, Fiebich BL, Berger M, Bauer J, Schulze-Osthoff K. The neuropeptide substance $P$ activates transcription factor NF-kB and kB-dependent gene expression in human astrocytoma cells. J Immunol. 1997;159:4952-8.

22. Fiebich BL, Schleicher S, Butcher RD, Craig A, Lieb K. The neuropeptide substance $P$ activates $\mathrm{p} 38$ mitogen-activated protein kinase resulting in IL-6 expression independently from NF-kB. J Immunol. 2000;165:5606-11.

23. Martin FC, Charles AC, Sanderson MJ, Merrill JE. Substance P stimulates IL-1 production by astrocytes via intracellular calcium. Brain Res. 1992;599:13-8.

24. Zhang $Y$, Berger A, Milne CD, Paige CJ. Tachykinins in the immune system. Curr Drug Targets. 2006;7:1011-20.

25. Laurenzi MA, Persson MA, Dalsgaard CJ, Haegerstrand A. The neuropeptide substance $P$ stimulates production of interleukin 1 in human blood monocytes: activated cells are preferentially influenced by the neuropeptide. Scand J Immunol. 1990;31:529-33.

26. Marriott I, Mason MJ, Elhofy A, Bost KL. Substance P activates NF-KB independent of elevations in intracellular calcium in murine macrophages and dendritic cells. J Neuroimmunol. 2000;102:163-71.

27. Lotz M, Vaughan JH, Carson DA. Effect of neuropeptides on production of inflammatory cytokines by human monocytes. Science. 1988;241:1218-21.

28. Ho WZ, Kaufman D, Uvaydova M, Douglas SD. Substance P augments interleukin-10 and tumor necrosis factor-a release by human cord blood monocytes and macrophages. J Neuroimmunol. 1996;71:73-80.

29. Yang S, Stepien D, Hanseman D, Robinson B, Goodman MD, Pritts TA, et al Substance $P$ mediates reduced pneumonia rates after traumatic brain injury. Crit Care Med. 2014;42:2092-100.

30. Teasdale G, Jennett B. Assessment of coma and impaired consciousness: a practical scale. Lancet. 1974;2:81-4.

31. Baker SP, O'Neill B, Haddon Jr W, Long WB. The Injury Severity Score: a method for describing patients with multiple injuries and evaluating emergency care. J Trauma. 1974;14:187-96.

32. Marshall LF, Marshall SB, Klauber MR, Van Berkum CM, Eisenberg $H$, Jane JA, et al. The diagnosis of head injury requires a classification based on computed axial tomography. J Neurotrauma. 1992;9:\$287-92.

33. Knaus WA, Draper EA, Wagner DP, Zimmerman JE. APACHE II: a severity of disease classification system. Crit Care Med. 1985;13:818-29.

34. Frutos Bernal E, Rubio Gil FJ, Martín Corral JC, Marcos Prieto LA, González Robledo J. [Prognostic factors in severe traumatic brain injury]. Med Intensiva. 2013;37:327-32. Spanish.

35. Petroni G, Quaglino M, Lujan S, Kovalevski L, Rondina C, Videtta W, et al. Early prognosis of severe traumatic brain injury in an urban Argentinian trauma center. J Trauma. 2010;68:564-70.

36. Wu X, Hu J, Zhuo L, Fu C, Hui G, Wang Y, et al. Epidemiology of traumatic brain injury in eastern China, 2004: a prospective large case study. J Trauma. 2008;64:1313-9.

37. Masson F, Thicoipe M, Aye P, Mokni T, Senjean P, Schmitt V, et al. Epidemiology of severe brain injuries: a prospective population-based study. J Trauma. 2001;51:481-9.

38. Ono J, Yamaura A, Kubota M, Okimura Y, Isobe K. Outcome prediction in severe head injury: analyses of clinical prognostic factors. J Clin Neurosci. 2001;8:120-3.

39. Park SW, Yan YP, Satriotomo I, Vemuganti R, Dempsey RJ. Substance $P$ is a promoter of adult neural progenitor cell proliferation under normal and ischemic conditions. J Neurosurg. 2007;107:593-9.

40. De Felipe C, Pinnock RD, Hunt SP. Modulation of chemotropism in the developing spinal cord by substance P. Science. 1995;267:899-902.

41. Delgado AV, McManus AT, Chambers JP. Exogenous administration of substance $P$ enhances wound healing in a novel skin-injury model. Exp Biol Med (Maywood). 2005;230:271-80.

42. Carthew HL, Ziebell JM, Vink R. Substance P-induced changes in cell genesis following diffuse traumatic brain injury. Neuroscience. 2012;214:78-83.

43. Maeda K, Nakai M, Maeda S, Kawamata T, Yamaguchi T, Tanaka C. Possible different mechanism between amyloid- $\beta$ (25-35)- and substance P-induced chemotaxis of murine microglia. Gerontology. 1997;43:11-5.

44. Monje ML, Toda H, Palmer TD. Inflammatory blockade restores adult hippocampal neurogenesis. Science. 2003;302:1760-5. 
45. Hoehn BD, Palmer TD, Steinberg GK. Neurogenesis in rats after focal cerebral ischemia is enhanced by indomethacin. Stroke. 2005;36:2718-24.

46. Das S, Basu A. Inflammation: a new candidate in modulating adult neurogenesis. J Neurosci Res. 2008;86:1199-208.

47. Gabrielian L, Helps SC, Thornton E, Turner RJ, Leonard AV, Vink R. Substance $P$ antagonists as a novel intervention for brain edema and raised intracranial pressure. Acta Neurochir Suppl. 2013;118:201-4.

48. Chavolla-Calderón M, Bayer MK, Fontán JJ. Bone marrow transplantation reveals an essential synergy between neuronal and hemopoietic cell neurokinin production in pulmonary inflammation. J Clin Invest. 2003;111:973-80.

49. Duffy RA. Potential therapeutic targets for neurokinin-1 receptor antagonists. Expert Opin Emerg Drugs. 2004;9:9-21.

50. Czéh B, Fuchs E, Simon M. NK1 receptor antagonists under investigation for the treatment of affective disorders. Expert Opin Investig Drugs. 2006;15:479-86.

51. Muñoz M, Rosso M, Coveñas R. The NK-1 receptor: a new target in cancer therapy. Curr Drug Targets. 2011;12:909-21.

52. Vink $R$, van den Heuvel $C$. Substance $P$ antagonists as a therapeutic approach to improving outcome following traumatic brain injury. Neurotherapeutics. 2010;7:74-80.

53. O'Connor TM, O'Connell J, O'Brien DI, Goode T, Bredin CP, Shanahan F. The role of substance P in inflammatory disease. J Cell Physiol. 2004;201:167-80.

54. Muñoz M, Coveñas R. Involvement of substance $P$ and the NK-1 receptor in human pathology. Amino Acids. 2014;46:1727-50.

55. Almeida TA, Rojo J, Nieto PM, Pinto FM, Hernandez M, Martín JD, et al. Tachykinins and tachykinin receptors: structure and activity relationships. Curr Med Chem. 2004;11:2045-81.

56. Shi HY, Hwang SL, Lee IC, Chen IT, Lee KT, Lin CL. Trends and outcome predictors after traumatic brain injury surgery: a nationwide population-based study in Taiwan. J Neurosurg. 2014;3:1-8.

57. Lu J, Marmarou A, Choi S, Maas A, Murray G, Steyerberg EW, et al. Mortality from traumatic brain injury. Acta Neurochir. 2005;95:281-5.

58. Kleinbaum DG, Kupper LL, Nizam A, Muller KE. Polynomial regression. In: Applied regression analysis and other multivariable methods. Belmont, CA: Brooks/Cole; 1998. p. 281-316.

\section{Submit your next manuscript to BioMed Central and take full advantage of:}

- Convenient online submission

- Thorough peer review

- No space constraints or color figure charges

- Immediate publication on acceptance

- Inclusion in PubMed, CAS, Scopus and Google Scholar

- Research which is freely available for redistribution 